\title{
Optimization Design of a Riser-Drill String Coupling System Based on CAE Techniques
}

\author{
Shiyao Qin, ${ }^{1}$ Ruiming Wang, ${ }^{1}$ Deyi Fu ${ }^{D},{ }^{1}$ and Gaowei Wang ${ }^{2}$ \\ ${ }^{1}$ State Key Laboratory of Operation and Control of Renewable Energy \& Storage Systems (China Electric Power Research \\ Institute Co., Ltd.), Beijing 100192, China \\ ${ }^{2}$ School of Mechanical Engineering, University of Science and Technology, Beijing, China \\ Correspondence should be addressed to Deyi Fu; fudeyi@epri.sgcc.com.cn
}

Received 27 October 2020; Revised 9 November 2020; Accepted 30 December 2020; Published 30 January 2021

Academic Editor: Yuqiang Xu

Copyright (C) 2021 Shiyao Qin et al. This is an open access article distributed under the Creative Commons Attribution License, which permits unrestricted use, distribution, and reproduction in any medium, provided the original work is properly cited.

In a riser-drill string coupling system, the drill string extends from platform to downhole, and its exterior tube is divided by mud line into two parts: riser for upside and borehole for downside. Due to such a pipe-in-pipe structure, an improved dynamic model is proposed to take the multipoint interactions between the inner and outer pipes into consideration. The dynamic responses of this system are analyzed by Computer Aided Engineering (CAE) techniques; specifically, it is numerically simulated in Abaqus; then, both the parametric sensitivity analysis and the main effect analysis are carried out in Isight to determine the optimization parameters and the optimization strategy. Moreover, six-sigma algorithm in Isight is applied to simultaneously drive the neighborhood cultivation genetic algorithm (NCGA) to conduct multiobjective optimization and drive the Monte Carlo method to analyze the stability of the obtained optimal solution. Based on the above investigations, a software package is developed via the secondary developments of both Abaqus and Isight. By this way, the optimization design of the riser-drill string coupling system based on dynamic analysis can be conducted effectively and efficiently.

\section{Introduction}

The exploitation of offshore petroleum resources is faced with complex ocean environment; hence, the reliability of equipment and the operation safety should be of high standard. Offshore drilling is different from onshore drilling, since drilling rigs and drilling mud reach wellhead through a riser system whose length is determined by the sea depth. A riser system can be viewed as an extension of borehole, since its bottom side joins with a blowout preventer, which is installed on the wellhead. The topside of the riser system is connected with a drilling platform or a drilling vessel via telescopic joint and flexible joint. The riser and borehole constitute an outer pipe within which a drill string system rotates. Above the mud line, the pipe-inpipe structure deflects under the effects of ocean loads, which triggers the intermittent contacts and frictions between the inner and outer pipes along the whole drilling tube system.
The investigations of the dynamics of the offshore drilling tube system trace back to 1970s. As the beginning, only the riser system was considered. According to both the fourth-order differential equation of Euler-Bernoulli beam and the Morison equation, Burke [1] built up a dynamic model of a riser system for $800 \mathrm{ft}$ sea depth. Based on Burke's work, scholars applied finite element method to analyze the riser dynamics for two-dimensional $[2,3]$ or three-dimensional conditions $[4,5]$. Thereafter, rather than using the Euler-Bernoulli beam, Yazdchi and Crisfeld [6] applied Reissner-Simo beam to develop the mathematical model of the riser system to enhance the analysis of shear deformation of the riser. Instead of using the beam models, Nair and Baddour [7] divided the riser system into pieces which were connected by a series of spring-damper units. In addition, Wang et al. [8] analyzed the drilling tube vibration under the influences of the drilling mud flowing. Liu et al. [9] discussed the wear of deepwater drilling riser. By further considering the contact nonlinearity between 
drill string and riser, the pipe-in-pipe structure for the drilling tube system raises the interests of scholars. Bueno and Morooka [10] designed an interaction model to calculate the contact force between drill string and riser. Harrison and Helle [11] proposed an equivalent model to calculate the combined stiffness of the inner and outer pipes. Liu et al. [12] introduced the gap-element to analyze the nonlinear mechanics of drill string. Mao et al. [13, 14] designed an experimental system to measure the dynamic responses of a riser system. Guo et al. [15] discussed the vibration suppression of a variable-length drilling riser system. The precise dynamic analysis of the riser-drill string coupling system is the precondition of its corresponding optimization design. Housner and Dixon [16] primarily conducted the optimization design to reduce the steel volumes of the pipe-in-pipe structure and thus to save the potential cost. Chang et al. [17] analyzed both the environmental influences and the operational factors for optimizing offshore drilling riser. In order to promote the calculation efficiency, Zheng and Yang [18] applied approximation method to optimize a compliant vertical access riser. Qin et al. [19] carried out optimization design of a deepwater riser based on parametric sensitivity analysis, and its optimal objective is to minimize the total tension. Yang et al. [20] presented an efficient optimization strategy for the design of the offshore riser by considering the fatigue life constraints. Aiming at minimizing the rotation angle of the lower flexible joint, Wang et al. [21] focused on the optimization of the top tension of the riser.

According to the aforementioned investigations, in this paper, a complete optimization flow about the riser-drill string coupling system is expected to be developed, which is based on the analyses of the dynamic responses of the pipein-pipe structure model. The multiobjective optimization method will be applied, and the reliability analysis will be integrated into the optimization design. The main purpose is to secure the safety and stability of the designed offshore drilling tube system when it works under the varied ocean environmental loads and the perturbations of system parameters.

The rest of this paper is organized as follows. Section 2 introduces the mathematical modeling of the riser-drill string coupling system, and the gap-element is introduced to simulate the intermittent interactions between the inner and outer pipes. The dynamic responses of the drilling tube system are numerically simulated by using Abaqus. In Section 3, the parametric sensitivity analyses and the main effect analyses are conducted to explore the optimization parameters and to determine the optimization strategy. The multiobjective optimization by using a combination of optimization algorithms is carried out successively. In Section 4, based on the secondary developments of both Abaqus and Isight, a software package is developed, which can be specially applied for the optimization design of the riser-drill string coupling system. At last, concluding remarks are provided in section 5 .

\section{Mathematical Modeling and Numerical Simulation}

The developed physical model for a part of a riser-drill string coupling system is shown in Figure 1. The deformation of the pipe-in-pipe structure under the effects of ocean loads is depicted in subplot (a), and a gap-element unit used to simulate the interactions between the inner and outer pipes is displayed in subplot (b).

During the mathematical modeling, on the one hand, Ekman drift theory [22], Airy wave theory [22], and Morison equation (1) are applied to describe the ocean loads acting on the riser. Meanwhile, the shear force, tension, gravity, and inertia force of the riser are also considered. On the other hand, the force analysis of the drill string is similar to the riser but without considering the direct influences of the ocean loads. In addition, the interactions between the drill string and the riser are described by the gap-elements. Therefore, the differential equations for the drilling tube system with the pipe-in-pipe structure can be written as

$$
\left\{\begin{array}{l}
\frac{\partial^{2}}{\partial z^{2}}\left[\mathrm{EI} \frac{\partial^{2} y}{\partial z^{2}}\right]+P \frac{\partial^{2} y}{\partial z^{2}}+\left(1-B_{f}\right) m g \frac{\partial y}{\partial z}+m \frac{\partial^{2} y}{\partial t^{2}}+\frac{1}{2} C_{d} D \rho\left(u_{w}+u_{c}-\frac{\partial y}{\partial t}\right)\left|u_{w}+u_{c}-\frac{\partial y}{\partial t}\right| \\
+\frac{1}{4} D^{2} \pi \rho\left[C_{m} a_{w}-\left(C_{m}-1\right) \frac{\partial^{2} y}{\partial t^{2}}\right]+H\left(y-y^{\prime}-G\right) F_{c-f}=0 \\
\frac{\partial^{2}}{\partial z^{\prime 2}}\left[\mathrm{EI}^{\prime} \frac{\partial^{2} y^{\prime}}{\partial z^{\prime 2}}\right]+P^{\prime} \frac{\partial^{2} y^{\prime}}{\partial z^{\prime 2}}+m^{\prime} g \frac{\partial y^{\prime}}{\partial z^{\prime}}+m^{\prime} \frac{\partial^{2} y^{\prime}}{\partial t^{2}}+H\left(y-y^{\prime}-G\right) F_{c-f}=0
\end{array}\right.
$$




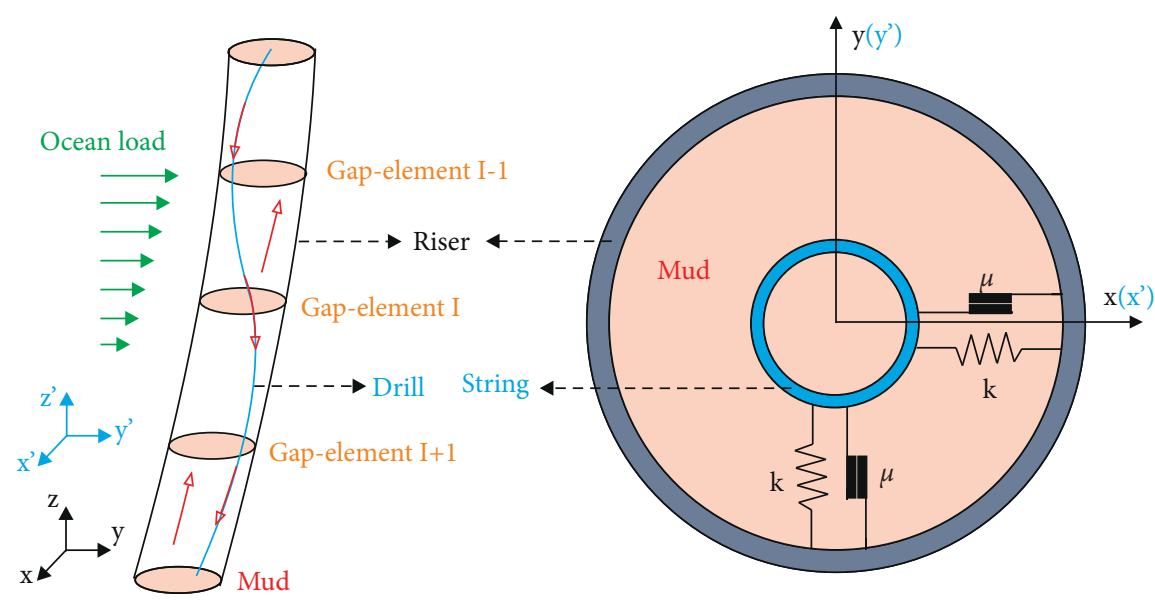

Figure 1: Physical model of a riser-drill string coupling system.

where $\mathrm{H}\left(y-y^{\prime}-G\right)$ is a Heaviside function; when $y-y^{\prime}-G \geq 0$, the interaction between the inner and outer pipes happens, and the corresponding interaction force is calculated as $F_{c-f}$.

$$
\begin{aligned}
H\left(y-y^{\prime}-G\right) & =\left\{\begin{array}{ll}
0 & \left(y-y^{\prime}-G<0\right) \\
1 & \left(y-y^{\prime}-G \geq 0\right)
\end{array},\right. \\
F_{c-f} & =K(z)\left(y-y^{\prime}-G\right)+\mu(z) K(z)\left(y-y^{\prime}-G\right),
\end{aligned}
$$

In addition, the boundary conditions for the drilling tube system can be summarized as

$$
\left\{\begin{array}{l}
y(0, t)=0 \\
E I(0) \frac{\partial^{2} y(0, t)}{\partial z^{2}}=k_{b} \frac{\partial y(0, t)}{\partial z} \\
y(L, t)=S \\
E I(L) \frac{\partial^{2} y(L, t)}{\partial z^{2}}=k_{t} \frac{\partial y(L, t)}{\partial z} \\
y^{\prime}(0, t)=A \sin (\Omega t) \\
\frac{\partial y^{\prime}(0, t)}{\partial z^{\prime}}=0 \\
y^{\prime}(L, t)=S \\
\frac{\partial y^{\prime}(L, t)}{\partial z^{\prime}}=0
\end{array}\right.
$$

The initial conditions of the drilling tube system are described as

$$
\left\{\begin{array}{l}
y(z, 0)=0, \\
\frac{\partial y(z, 0)}{\partial t}=0, \\
y^{\prime}\left(z^{\prime}, 0\right)=0, \\
\frac{\partial y^{\prime}\left(z^{\prime}, 0\right)}{\partial t}=0,
\end{array}\right.
$$

In addition, the borehole is assumed to be vertical and static. Two independent coordinate systems are applied to describe the movements of the riser system $(x-y-z)$ and the drill string system $\left(x^{\prime}-y^{\prime}-z^{\prime}\right)$, respectively. All the system parameters are listed in Table 1.

Based on the developed mathematical model, Abaqus is applied to carry out the numerical simulation. Specifically, the beam element, B31, is used to construct both the inner and outer pipes; the edge-to-edge contact model is chosen to simulate the interactions of pipes. The connector element, CONN3D2 with joint-rotation property, is used to describe the upper and lower flexible joints. The ocean loads are set by the Aqua module with the sea current velocity decreasing exponentially from the sea level to the mud line. Additionally, to eliminate the disturbance of transient dynamic behavior, each numerical simulation lasts 100 periods of the sea wave, and only the last 20 periods are used to analyze the system dynamics, which ensures this system reaching its dynamic stable status. A numerical simulation case is shown in Figure 2. In subplot (a), the dynamic stable status of the whole riser-drill string coupling system is displayed, where its lateral size is enlarged 5 times for more clear observation. The maximal deflection region is marked as red, which locates around the $1 / 3$ sea depth. Subplot (b) is an enlarged view to show the drill string-riser interactions. 
TABLE 1: Nomenclature list.

$\mathbf{K}_{\mathbf{w}}$ : Factor of wind speed

z: Distance from mud line $(\mathrm{m})$

$\mathbf{h}_{\mathbf{w}}$ : Amplitude of sea wave $(\mathrm{m})$

$\omega$ : Circular frequency of sea wave $(\mathrm{rad} / \mathrm{s})$

D: External diameter of riser $(\mathrm{m})$

$\mathbf{m}$ : Mass of riser per unit length $(\mathrm{kg})$

$\mathbf{E} I^{\prime}$ : Flexural stiffness of drill string $\left(\mathrm{Nm}^{2}\right)$

$m^{\prime}$ : Mass of drill string per length $(\mathrm{kg})$

S: Top drift of riser (m)

$\mathbf{k}_{\mathbf{b}}$ : Stiffness of lower joint $(\mathrm{Nm} / \mathrm{rad})$

$\mathbf{v}_{\mathbf{w}}$ : Wind speed $(\mathrm{m} / \mathrm{s})$

L: Water depth $(\mathrm{m})$

$\mathbf{T}_{\mathbf{w}}$ : Period of sea wave (s)

$\mathrm{C}_{\mathrm{d}}$ : Drag coefficient

$\rho$ : Sea-water density $\left(\mathrm{kg} / \mathrm{m}^{3}\right)$

$\mathbf{B}_{\mathrm{f}}$ : Buoyancy factor

$P^{\prime}$ : Tension of drill string $(\mathrm{N})$

K: Contact stiffness $(\mathrm{N} / \mathrm{m})$

A: Amplitude of drill bit (m)

$\mathbf{k}_{\mathbf{t}}$ : Stiffness of top joint $(\mathrm{Nm} / \mathrm{rad})$

$\mathbf{v}_{\mathbf{t}}$ : Current speed $(\mathrm{m} / \mathrm{s})$

$\varphi$ : Geographic latitude ( $\left.{ }^{\circ}\right)$

$\mathbf{L}_{\mathbf{w}}$ : Sea wavelength $(\mathrm{m})$

$\mathrm{C}_{\mathrm{m}}$ : Inertial coefficient

EI: Flexural stiffness of riser $\left(\mathrm{Nm}^{2}\right)$

P: Tension of riser $(\mathrm{N})$

g: Gravitational acceleration $\left(\mathrm{m} / \mathrm{s}^{2}\right)$

$\mu$ : Friction coefficient

$\Omega$ : Frequency of drill bit ( $\mathrm{rad} / \mathrm{s})$

G: Initial gap between pipes (m)

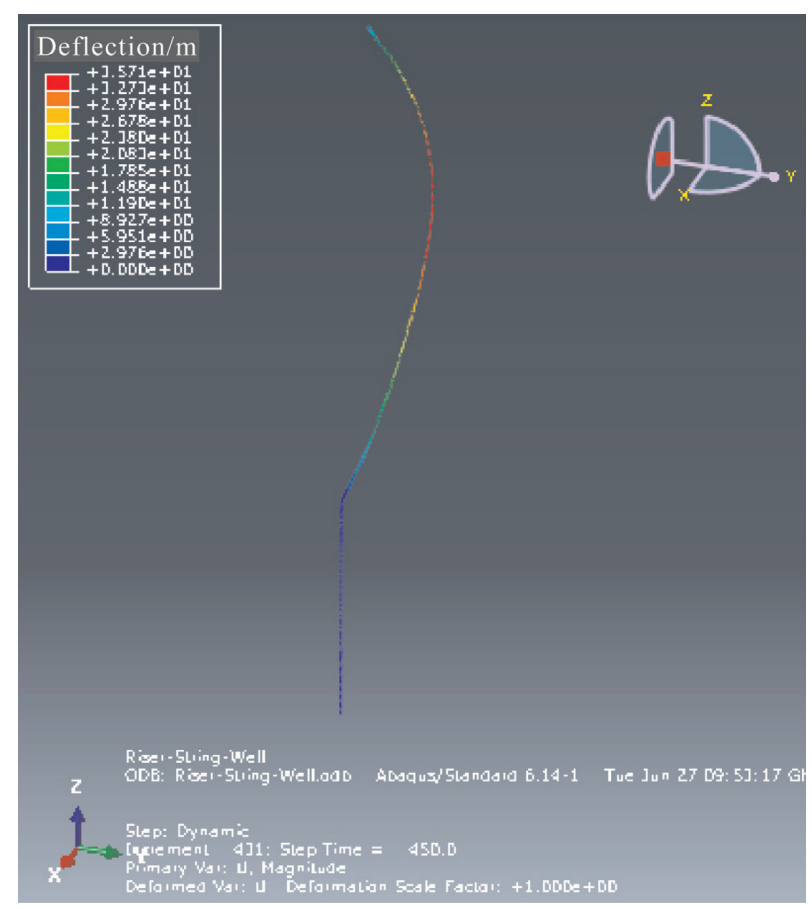

(a)

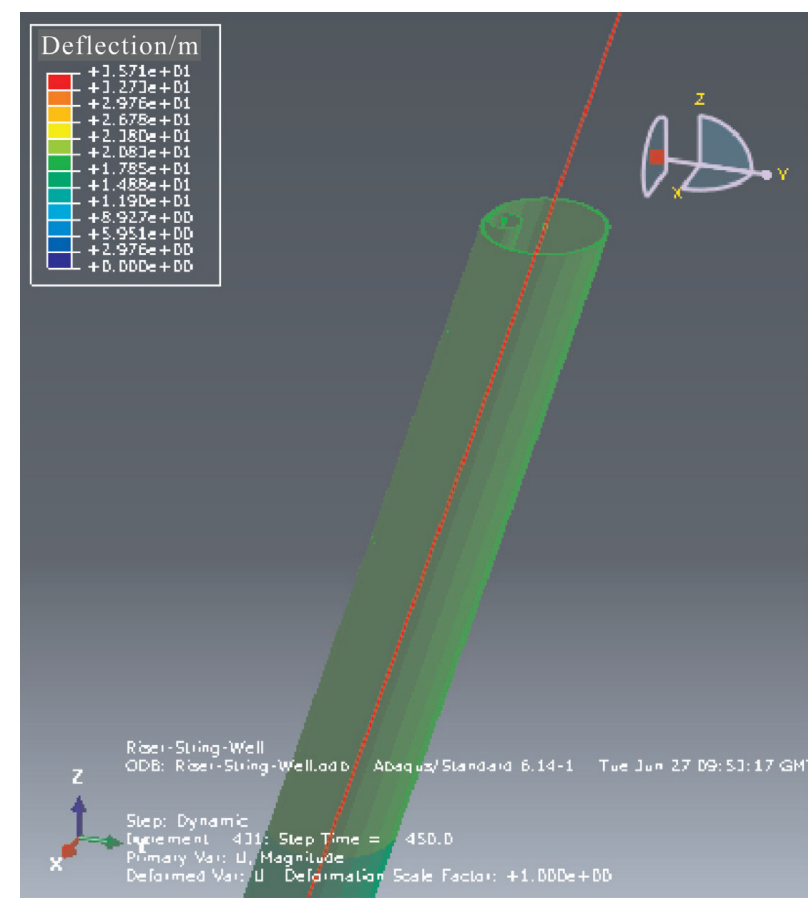

(b)

Figure 2: Numerical simulation using Abaqus. 


\section{Optimization Design Based on Dynamic Responses}

In this section, the finite element model developed in Abaqus is embedded into Isight via its data interface specialized for Abaqus, and thus the optimization parameters designed by Isight can be sent to Abaqus; meanwhile, the dynamic responses of the riser-drill string system simulated by Abaqus can also be transferred into Isight for further optimization.

3.1. Parametric Sensitivity Analyses. Based on the numerical simulation introduced in Section 2, parametric sensitivity analyses for the riser-drill string coupling system can be carried out. Six system parameters are considered: diameter of riser, thickness of riser, top drift of riser, hanging load of drill string, top tension of riser, and rotational stiffness of flexible joint. For the purpose of comparison, the dynamic responses of a standard case are simulated primarily [15], and then the six system parameters are modified successively to compare their influences on the system dynamic responses. All the obtained results of numerical simulations are plotted in Figures 3-5. Figure 3 shows the distributions of (a) the deflection, (b) bending moment, (c) Mises stress, and (d) the rotation angle for the riser, respectively. Figure 4 displays the distributions of (a) the deflection, (b) bending moment, and (c) Mises stress for the drill string, respectively. Figure 5 shows the time histories of rotation angles of (a) the upper and (b) lower flexible joints, respectively. According to the distinguishing influences of these six system parameters, the optimization strategies, such as thickening the riser wall, increasing the riser diameter, decreasing the top drift, increasing the hanging load of drill string, increasing the top tension of riser, and increasing the rotational stiffness of flexible joint, are suggested. Since, by applying these optimization strategies, the tube deflection is restricted, both the bending moment and Mises stress decrease, and the rotations of the riser and the flexible joints are also limited effectively.

3.2. Main Effect Analysis. According to field practices, four main constraint conditions for the system dynamic responses should be considered during optimization design: the maximal Mises stress is less than $67 \%$ of yield stress of the pipe material; the maximal deflection of the tube system is less than $2 \%$ of the sea depth; the maximal rotation angles of the upper and lower flexible joints are controlled within $5^{\circ}$ and $2^{\circ}$, respectively. Based on the proposed constraint conditions, the correlations between the optimization parameters and the constraint conditions are investigated. Specifically, the design of experiment method (DOE) and the Latin Hypercube sampling technique are applied. The six optimization parameters are set to vary within $\pm 50 \%$ around their standard values; 1000 sampling cases are tested. The obtained correlations are shown in Table 2. Specifically, the maximal Mises stress is mainly determined by the hanging load of drill string, and they are positive correlation. The maximal deflection is mainly determined by the top drift of riser; meanwhile, large top tension of the riser and large hanging load of the drill string can also restrict the pipe deflection. The increasing diameter and the top tension of the riser can decrease the maximal rotation angle of the upper flexible joint. In particular, since the rotation angle of the lower flexible joint is negative, the optimization target is to decrease its absolute value. For this purpose, decreasing the top drift of riser, or increasing the top tension of riser, or the hanging load of drill string, or the rotational stiffness of the lower joint is effective to control the rotation of the lower flexible joint.

Meanwhile, several contradiction effects are also observed in Table 2. For instance, the increasing hanging load of drill string will be of benefit for the controls of the riser deflection and the rotations of the upper and lower joints, but it will also lead to high Mises stress. Such contradiction effects among different optimization objectives approve the necessity of the application of multiobjective optimization, since its basic principle is to search the optimal solutions via balancing these contradictory optimization objectives. In order to conduct multiobjective optimization, multiple objectives are also needed. According to these four constraint conditions, the corresponding optimization objectives are inferred as simultaneously minimizing the pipe deflection, the Mises stress, and the rotation angles of both the upper and lower flexible joints.

3.3. Multiobjective Optimization. By considering the six optimization parameters, four constraint conditions, and four optimization objectives, the optimization of the riserdrill string coupling system is a multiparameter multiconstraint and multiobjective optimization. Moreover, in order to further secure the stability of the obtained optimization solutions, the influences of the parameter perturbation should be considered during optimization design. Therefore, a combination of optimization algorithms is designed. Specifically, NCGA is chosen to conduct the optimization design. Monte Carlo method is applied to determine the reliability of the obtained optimization solutions. Both the NCGA and the Monte Carlo method are integrated by the six-sigma method, since it is able to simultaneously drive the NCGA and Monte Carlo method to secure that all the confirmed optimization designs satisfy the minimal requirement for reliability. To conduct the multiobjective optimization effectively, the pipe-in-pipe model developed in Abaqus is directly imported into Isight in which a variety of optimization algorithms have already been integrated.

For a practical multiobjective optimization design of a riser-drill string coupling system, all the optimization parameters are allowed to fluctuate within $\pm 10 \%$ around the optimization designs, and the minimal requirement for reliability is set as $98 \%$. By applying the combination of the optimization algorithms, 1000 parameter combinations are analyzed, and the obtained results are projected to a threedimensional phase space (see Figure 6). All the 1000 designs are divided into three types: failed designs, general designs, and optimization designs. Specifically, the failed designs (red 




(a)

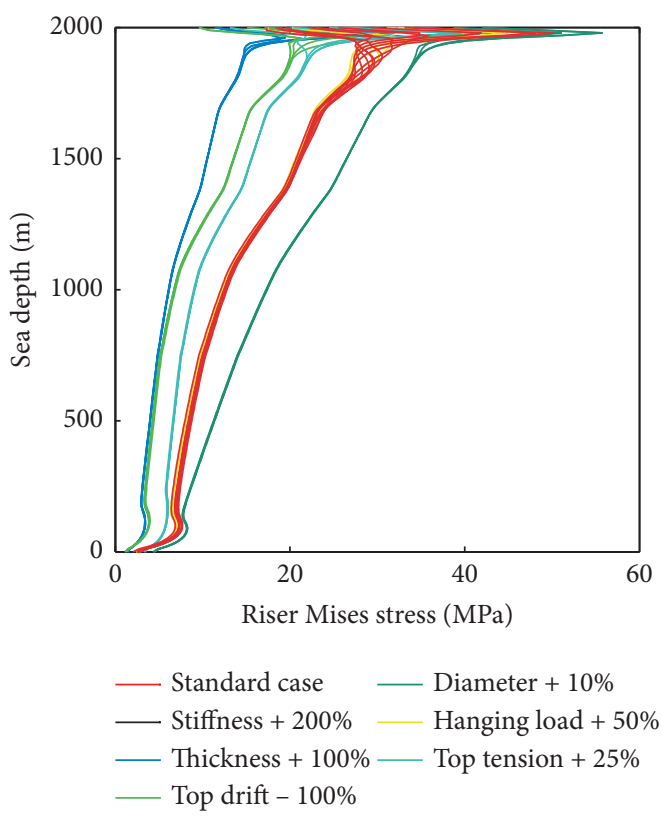

(c)

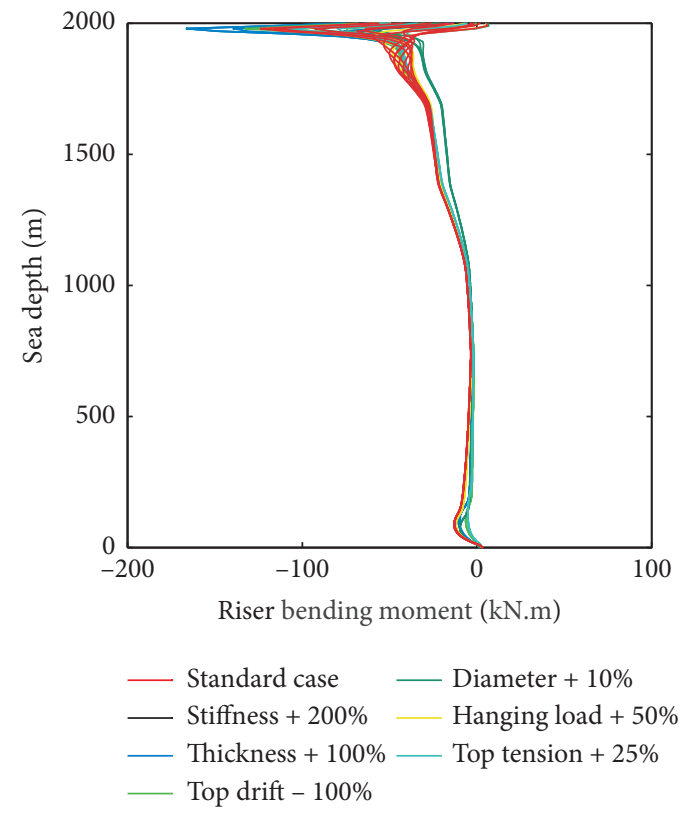

(b)

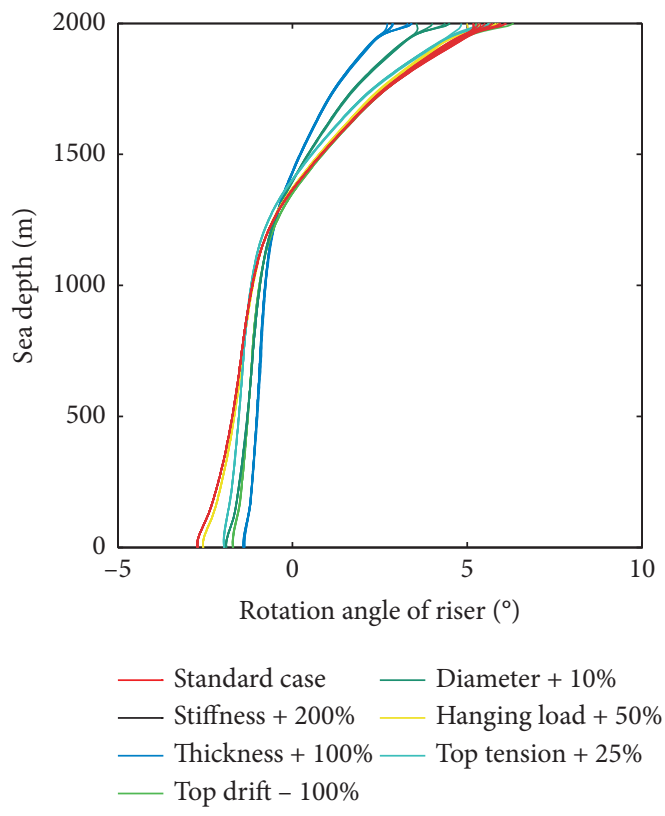

(d)

FIGURE 3: Comparison of dynamic responses for the riser system with different parameters.

dots) may violate constraint conditions or dissatisfy reliability requirement or cannot converge. The general designs (black dots) satisfy the constraints and reliability requirement, but they are not optimal from a mathematical point of view, while the optimization designs (blue dots) are suggested according to comprehensive comparisons among all the feasible solutions. Moreover, all the optimization designs (blue points) constitute a Pareto front which is a surface in the three-dimensional phase space. This Pareto front indicates a basic distribution trend of the optimization designs based on multiobjective optimization.

\section{Secondary Developments of Abaqus and Isight}

From dynamic analysis to multiobjective optimization, the whole procedure of the optimization design of a riser-drill string coupling system has been introduced in detail, which can be further summarized as the flow chart shown in Figure 7.

Following this flow chart, a software package is developed via the secondary developments of both Abaqus and Isight. Figure 8 displays the framework of the newly developed 


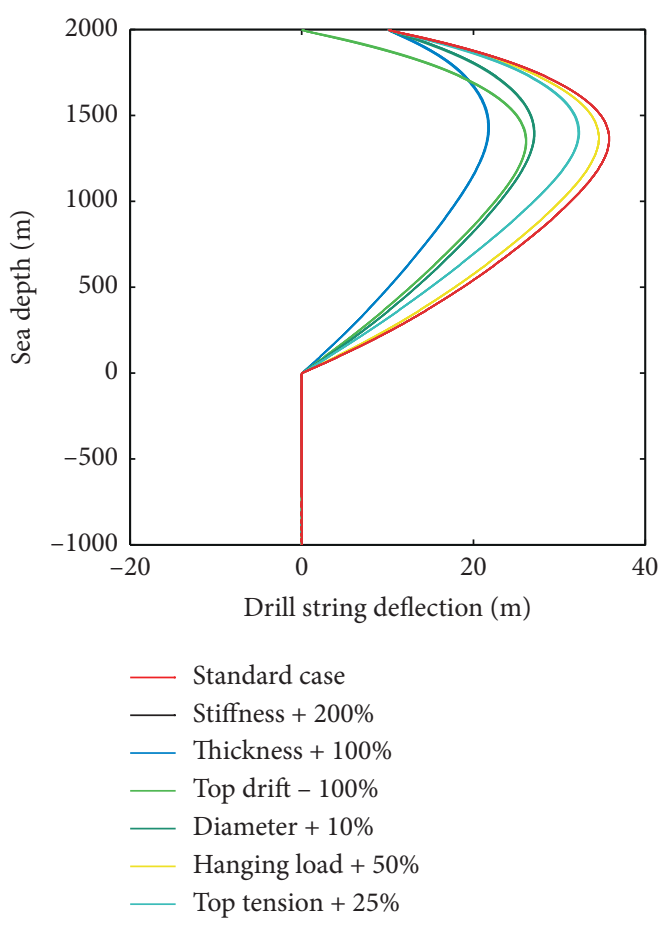

(a)



(b)



(c)

Figure 4: Comparison of dynamic responses for the drill string with different parameters.

software package, which consists of 10 function modules. Specifically, four function modules are developed based on Abaqus, including parametric modeling, data analysis, dynamic simulation, and data saving. Six other optimization modules are extracted from Isight, including DOE, NCGA, and Monte Carlo analysis of the pipe-in-pipe structure model built in Abaqus, and the corresponding NCGA, Monte Carlo, and six-sigma analysis of the approximation model which is developed by using the radial basis neural network analysis of all the obtained results of numerical simulations. In particular, the accuracy of the approximation model mainly depends on the quality and quantity of the obtained simulation results; hence, it can be upgraded continuously as more numerical simulations are conducted. 



(a)

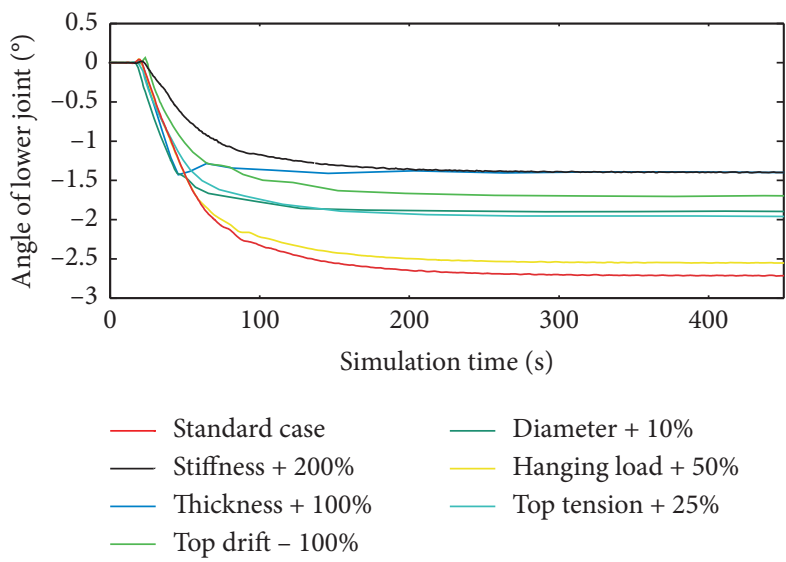

(b)

Figure 5: Comparison of time series for the upper and lower joints with different parameters.

TABLE 2: Effect correlations between the input and output variables.

\begin{tabular}{|c|c|c|c|c|c|c|c|}
\hline \multirow[b]{2}{*}{ Output } & \multicolumn{7}{|c|}{ Input } \\
\hline & $\begin{array}{c}\text { Riser } \\
\text { diameter }\end{array}$ & $\begin{array}{c}\text { Riser } \\
\text { thickness }\end{array}$ & $\begin{array}{l}\text { Top } \\
\text { drift }\end{array}$ & $\begin{array}{l}\text { Hanging } \\
\text { load }\end{array}$ & $\begin{array}{c}\text { Top } \\
\text { tension }\end{array}$ & $\begin{array}{c}\text { Stiffness of lower } \\
\text { joint }\end{array}$ & $\begin{array}{c}\text { Stiffness of upper } \\
\text { joint }\end{array}$ \\
\hline Maximal Mises stress & 0.06 & -0.12 & 0.05 & 0.95 & -0.14 & 0.03 & 0.04 \\
\hline Maximal deflection & -0.18 & -0.09 & 0.79 & -0.26 & -0.41 & 0.01 & -0.05 \\
\hline $\begin{array}{l}\text { Maximal angle of upper } \\
\text { joint }\end{array}$ & -0.65 & 0.01 & -0.17 & -0.34 & -0.52 & -0.01 & -0.17 \\
\hline $\begin{array}{l}\text { Maximal angle of lower } \\
\text { joint }\end{array}$ & 0.04 & 0.02 & -0.62 & 0.41 & 0.55 & 0.24 & 0.06 \\
\hline
\end{tabular}

When a new study case is analyzed by using this software package, the parametric modeling is applied primarily, and a pipe-in-pipe structure model can be directly built up based on the input system parameters; see Figure 9(a). After conducting the numerical simulations, nine dynamic responses about the drilling tube system are displayed; see Figure 9(b). Subsequently, both the developed pipe-in-pipe structure model and the obtained results of numerical simulations are imported into the optimization modules; and the optimization design starts by calling the corresponding Isight template which has already been integrated into this software package; see Figure 9(c). However, the optimization design based on the pipe-in-pipe structure model is generally time-consuming. Under such circumstances, the optimization module using the approximation model can be used to replace the corresponding optimization of the structure model; see Figure $9(\mathrm{~d})$. 


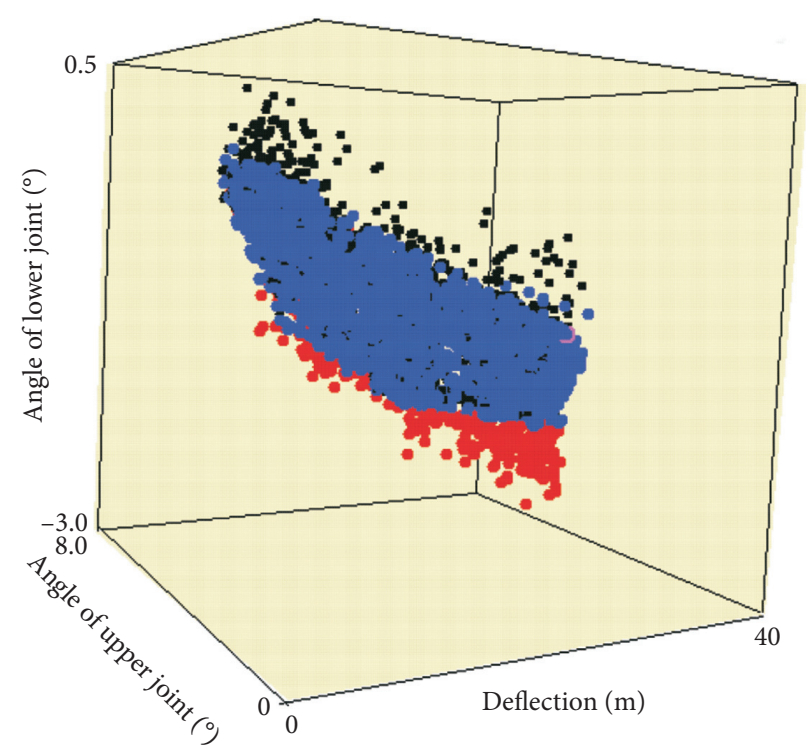

Figure 6: Pareto front obtained by multiobjective optimization.
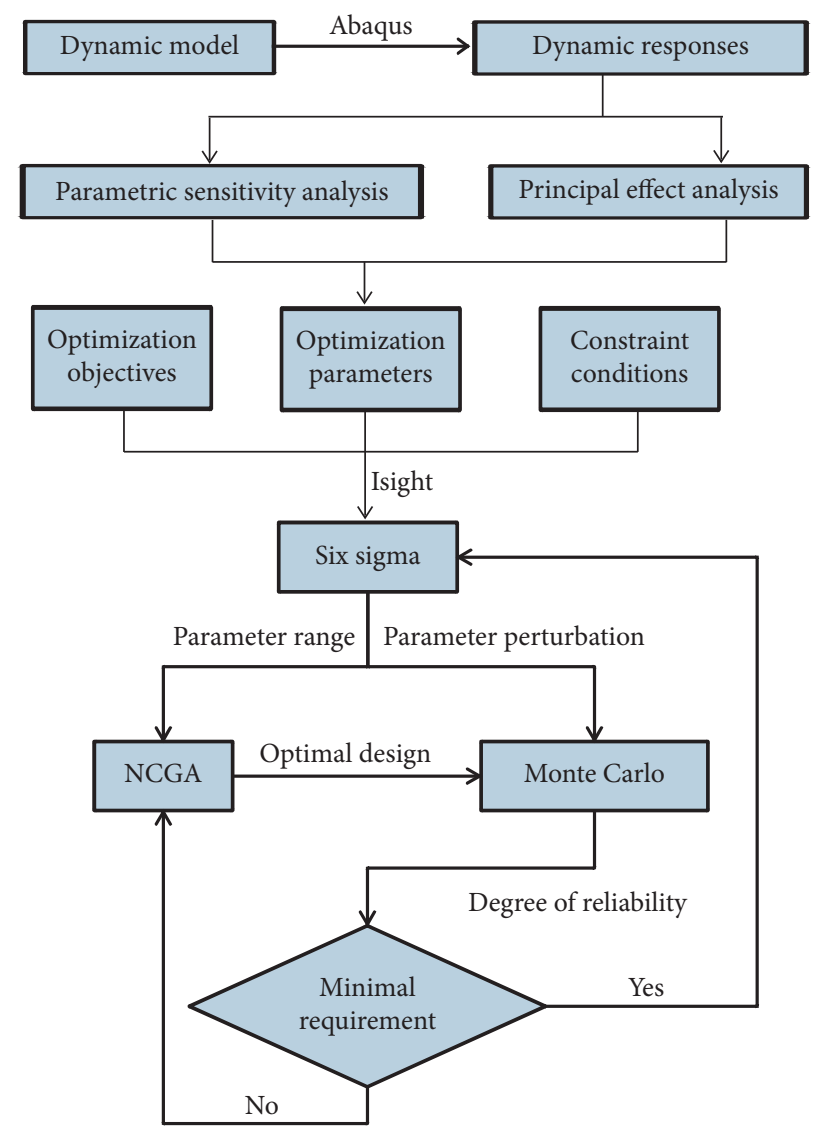

FIGURE 7: Flow chart of the software package for optimization design. 




FIGURE 8: Interface for the optimization design of a riser-drill string coupling system.


Figure 9: Main function modules of the software package.

\section{Concluding Remarks}

In this paper, the dynamic model of a riser-drill string coupling system with pipe-in-pipe structure was proposed. The interactions between the inner and outer pipes were considered into the dynamic model via introducing a series of gap-elements. Based on the numerical simulations in Abaqus, the parametric sensitivity analyses were carried out. In order to secure the offshore drilling tube system working in safe conditions, the operations, such as thickening the riser wall, increasing the riser diameter, limiting the top drift, increasing the hanging load of drill string, enhancing the top tension of riser, and increasing the rotational stiffness of the flexible joints, were suggested.

According to the main effect analyses, the top drift of riser, the top tension of riser, and the hanging load of drill string were proved as the three most significant parameters for the system optimization design. A combination of 
optimization algorithms, including NCGA, Monte Carlo method, and six-sigma method, was designed, based on which a group of optimization designs were explored, and they constituted a Pareto front which indicated a basic distribution trend of the optimization designs.

Based on the secondary developments of both Abaqus and Isight, a software package was developed specially for the optimization design of offshore drilling tube system. Ten function modules, including parametric modeling, dynamic analysis, and optimization design, had been integrated into this software package.

For the future work, the coupling effect of drilling fluid in the pipe-in-pipe structure will be taken into consideration; the fatigue damage of the drilling tube system is expected to be analyzed by using Fe-safe; meanwhile, the software package will also be upgraded correspondingly. With the further improvements of this software package, it is expected to be of benefit for offshore drilling engineers to conduct the optimization designs of offshore drilling tube systems with high reliability and high efficiency.

\section{Data Availability}

All data, models, or codes generated or used during the study are available from the corresponding author upon request.

\section{Conflicts of Interest}

The authors declare that they have no conflicts of interest.

\section{Acknowledgments}

This work was supported by the National Key Research and Development Program of China (2018YFB0904005), Science and Technology Project of State Grid (SGDK0000NYJS1803505), the National Natural Science Foundation of China (Grant no. 51904018), and the Fundamental Research Funds for the Central Universities (Grant no. FRF-TP-18-054A1).

\section{References}

[1] B. G. Burke, "An analysis of marine risers for deep water," in Proceedings of the Offshore Technology Conference, Houston, TX, USA, April 1973.

[2] M. H. Patel, S. Sarohia, and K. F. Ng, "Finite-element analysis of the marine riser," Engineering Structures, vol. 6, no. 3, pp. 175-184, 1984.

[3] B. Yue, K. C. Man, and D. Walters, "Tension and expansion analysis of pipe-in-pipe risers: part B finite element modeling," in Proceedings of the International Offshore and Polar Engineering Conference, Anchorage, AK, USA, June 2013.

[4] M. M. Bernitsas, J. E. Kokarakis, and A. Imron, "Large deformation three-dimensional static analysis of deep water marine risers," Applied Ocean Research, vol. 7, no. 4, pp. 178-187, 1985.

[5] Y. Bae and M. M. Bernitsas, "Importance of nonlinearities in static and dynamic analyses of marine risers," in Proceedings of the International Offshore and Polar Engineering Conference, Hague, Netherlands, June 1995.
[6] M. Yazdchi and M. A. Crisfeld, "Nonlinear dynamic behavior of flexible marine pipes and risers," International Journal for Numerical Methods in Engineering, vol. 54, pp. 1265-1308, 2001.

[7] W. R. Nair and R. E. Baddour, "Three-dimensional dynamics of a flexible marine riser undergoing large elastic deformations," Multibody System Dynamics, vol. 10, pp. 393-423, 2003.

[8] Y. Wang, D. Gao, and J. Fang, "Static analysis of deep-water marine riser subjected to both axial and lateral forces in its installation," Journal of Natural Gas Science and Engineering, vol. 19, pp. 84-90, 2014.

[9] X. Liu, G. Chen, Y. Chang, L. Zhang, and K. Liu, "Study on deepwater drilling riser wear," in Proceedings of the Offshore Technology Conference Asia, Kuala Lumpur, Malaysia, March 2017.

[10] R. C. S. Bueno and C. K. Morooka, "Analysis method for contact forces between drillstring-well-riser," in Proceedings of the International Petroleum Conference and Exhibition of Mexico, Veracruz, Mexico, October 1994.

[11] R. I. Harrison and Y. Helle, "Understanding the response of pipe-in-pipe deepwater riser systems," in Proceedings of the International Offshore and Polar Engineering Conference, Lisbon, Portugal, July 2007.

[12] J.-B. Liu, H. Ding, and X. Zhang, "Application of gap element to nonlinear mechanics analysis of drillstring," Journal of Zhejiang University Science, vol. 3, no. 4, pp. 440-444, 2002.

[13] L. Mao, Q. Liu, S. Zhou, G. Wang, and Q. Fu, "Deep water drilling riser mechanical behavior analysis considering actual riser string configuration," Journal of Natural Gas Science and Engineering, vol. 33, pp. 240-254, 2016.

[14] L. Mao, Q. Liu, S. Zhou, W. Jiang, Z. Liu, and T. Peng, "Vortex-induced vibration mechanism of drilling riser under shear flow," Petroleum Exploration and Development, vol. 42, no. 1, pp. 112-118, 2015.

[15] F. Guo, Y. Liu, F. Luo, and Y. Wu, "Vibration suppression and output constraint of a variable length drilling riser system," Journal of the Franklin Institute, vol. 356, no. 3, pp. 1177-1195, 2019.

[16] M. Housner and M. Dixon, "Optimized design of pipe-in-pipe systems," in Proceedings of the Offshore Technology Conference, Houston, TX, USA, February 2003.

[17] Y. Chang, G. Chen, and L. Xu, "Influential factors for the design of ultra-deepwater drilling risers," Petroleum Exploration and Development, vol. 36, no. 4, pp. 523-528, 2009.

[18] W. Zheng and H. Yang, "Dynamic response optimization of a compliant vertical access riser," Ship Science \& Technology, vol. 32, no. 2, pp. 115-119, 2010.

[19] W. Qin, Z. Kang, and Y. Kang, "Free standing hybrid riser global parametric sensitivity analysis and optimum design," in Proceedings of the International Conference on Ocean, Offshore and Arctic Engineering, Rotterdam, Netherlands, October 2011.

[20] H. Yang, H. Li, and H. Park, "Optimization design for steel catenary riser with fatigue constraints," International Journal Offshore and Polar Engineering, vol. 21, no. 4, pp. 302-307, 2011.

[21] Y. Wang, D. Gao, and J. Fang, "Optimization analysis of the riser top tension force in deepwater drilling: aiming at the minimum variance of lower flexible joint deflection angle," Journal of Petroleum Science and Engineering, vol. 146, pp. 149-157, 2016.

[22] O. M. Faltinsen, Sea Loads on Ships and Offshore Structures, Cambridge University Press, Cambridge, England, 1998. 